\title{
Effect of Thin Polymer Layers on Mechanical Properties of Metal Surfaces
}

\section{M.O. Kaptakov}

Moscow Aviation Institute (National Research University), Volokolamskoeshosse, 4, 125993, Moscow, Russia mkaptakov@mail.ru

Article History: Received: 11 January 2021; Accepted: 27 February 2021; Published online: 5 April 2021

\begin{abstract}
A study of the effect of epoxy-polyester powder coatings on the mechanical properties of plates made of rolled sheet steel has been carried out. The effect of a coating with a thickness of about $100 \mu \mathrm{m}$ on the mechanical properties of samples with a thickness of 0.7-1.5 mm was considered. Tests carried out at room and elevated temperatures showed that thin coatings insignificantly affect the mechanical properties of plates in bending and tensile tests. In particular, the stiffness of the plates under tension and bending practically does not change in the presence of coatings, despite the fact that the modulus of elasticity determined in tests of steel plates with coatings is always slightly lower than the Young's modulus of steel, due to the increased thickness of the samples, determined taking into account the presence of coatings. In contrast, in compressive strength tests, the effect of coatings is significant. In the supercritical deformation mode, the bearing capacity of the coated plates is significantly reduced, and their critical buckling load is 1.2-2.3 times lower (depending on the substrate thickness) in comparison with uncoated specimens. This effect can be explained by the influence of residual temperature stresses arising in the samples after the deposition of coatings.
\end{abstract}

Keywords: Polymer coatings, strength, steel plates, compression.

\section{Introduction}

The study of the mechanical properties of materials and coatings is an important task from the point of view of ensuring their strength and wear resistance during operation [1-10]. Polymer protective coatings are widely used in various fields of technology [11-21]to protect structural elements from corrosion, to provide electrical insulation, to control the frictional characteristics of surfaces, for decorative purposes, etc.[22-30].Determination of the elastic modulus, strength and other mechanical properties of coatings can be carried out by micro / nanoindentation methods or in bending tests of specimens with coatings with measurement of residual deformations on specimens with a one-sided coating, in tensile tests, when conducting direct tests of thin filmcoatings, or by studying the nature of warpage of coatings on compliant substrates, etc. [31-39].

\section{Experimental techniques}

The tests were carried out on specimens in the form of plates $120 \mathrm{~mm}$ long, $12 \mathrm{~mm}$ wide and $0.7 \mathrm{~mm}, 0.9 \mathrm{~mm}$, $1.2 \mathrm{~mm}$, and $1.5 \mathrm{~mm}$ thick (Fig. 1). The plate material is rolled sheet steel (unalloyed structural steel with a low carbon content). The surface of the plates was electrostatically applied with an epoxy-polyester powder coating. Before applying the coatings, the steel surface was degreased and phosphated. Coating was carried out in a Gema paint booth (Switzerland). Drying was carried out at a temperature of $120^{\circ} \mathrm{C}$ for no more than 5 minutes. Polymerization of the sprayed layer was carried out in a heat chamber at a temperature of $150^{\circ} \mathrm{C}$ for $30 \mathrm{~min}$. Samples were cooled in air for several hours. The thickness of the coatings on the samples was about $100 \mu \mathrm{m}$ with a scatter of values of $\pm 30 \mu \mathrm{m}$. The thickness of the coatings was measured with a micrometer. Were made batches of samples with different thickness of the substrate with coatings and without coatings for testing bending, tensile and stability at room and at elevated temperatures. Each batch for each type of test consisted of five samples.

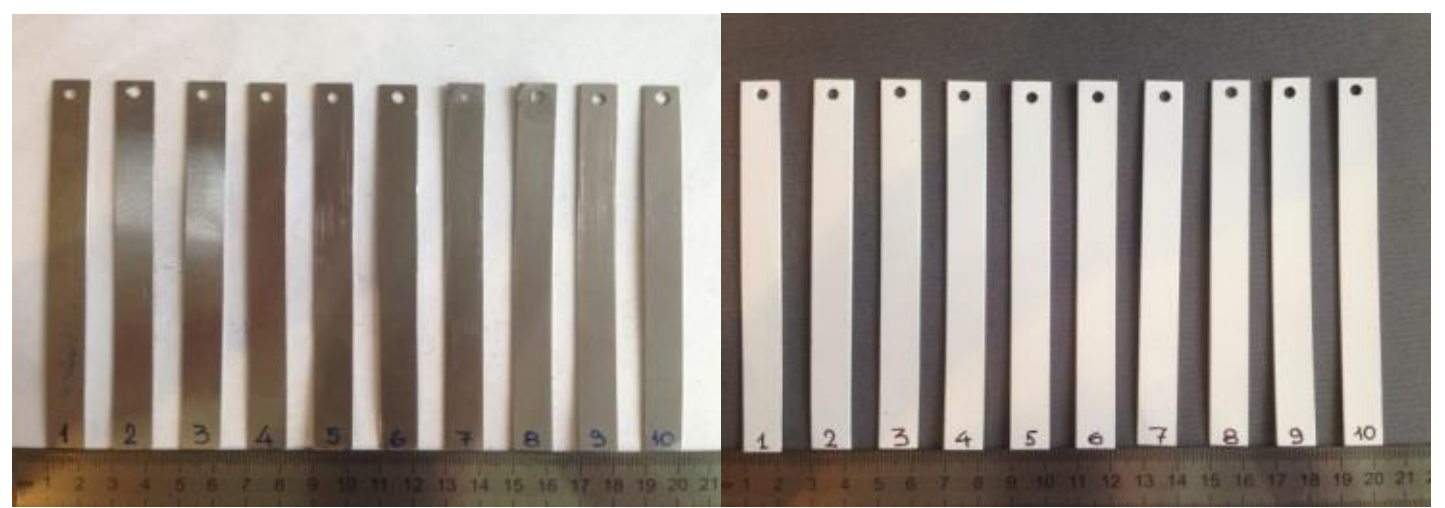

Fig. 1. Lots of samples in the form of steel plates without coatings (a) and with a powder epoxy-polyester coating (b).

Mechanical tests were carried out on an Instron 5969 (UK) setup with Bluehill 3 software. In the three-point bending test, the distance between the supports was $100 \mathrm{~mm}$. The test speed was $1 \mathrm{~mm} / \mathrm{min}$. To accurately 
measure the displacements of the plate during bending, a contact extensometer with a base of $50 \mathrm{~mm}$ was used, which was attached to a deflectometer installed in the center under the bent sample. Bending tests were carried out up to a maximum strain on the stretched fibers of $0.1 \%$. As a result of bending tests, the elastic modulus was determined. The program automatically selected the most typical interval on the stress-strain diagram to determine the elastic modulus of the samples.

In tensile tests, the length of the working part of the samples was $80 \mathrm{~mm}$. The tests were carried out at a speed of $0.5 \mathrm{~mm} / \mathrm{min}$ at the linear stage of deformation and at a speed of $3 \mathrm{~mm} / \mathrm{min}$ at the stage of plastic deformation and fracture. In the tests, a video extensometer with a measurement base of $50 \mathrm{~mm}$ was used, therefore, the stress-strain diagram was built with a high accuracy in measuring deformations up to the destruction of the samples.

When tested for loss of stability in compression, the length of the working part of the sample (distance between the grips) was $86 \mathrm{~mm}$. The test speed was $1 \mathrm{~mm} / \mathrm{min}$. As a result of the tests, a diagram of the dependence of displacements on the applied compressive load in the linear region of deformation of the sample and in the mode of supercritical deformations after loss of stability was constructed. The moment of buckling was established visually.

Elevated temperature tests were carried out using a climatic chamber. The test temperature was 70C. Exposure of the samples at an elevated temperature after their installation in the grips and before the start of testing was 5 minutes. Tensile tests at elevated temperatures used a contact extensometer with a base of $25 \mathrm{~mm}$.

\section{Results and discussion}

A comparison of typical load-displacement diagrams obtained for specimens of different thicknesses with and without coatings in bending tests is shown in Figure 2. Each diagram shown in this figure is obtained by averaging experimental data for five specimens of the same type. It can be seen that the stiffness of the plates (the slope of the diagrams) changes insignificantly in the presence of coatings on them. However, if we recalculate the modulus of elasticity of the plates according to the results of these tests, then for specimens with coatings it will always be lower than specimens without coatings due to their increased thickness, determined taking into account the presence of coatings (see Table 1). Provided high-precision measurements of plate deflections and loads, this type of test can be used to identify the elastic modulus of coatings. In particular, the Young's modulus can be found for the coatings under study, which was about $3 \mathrm{GPa}$. However, from the point of view of calculating the stress-strain state of structures, the established insignificant effect of coatings in most cases can be neglected.

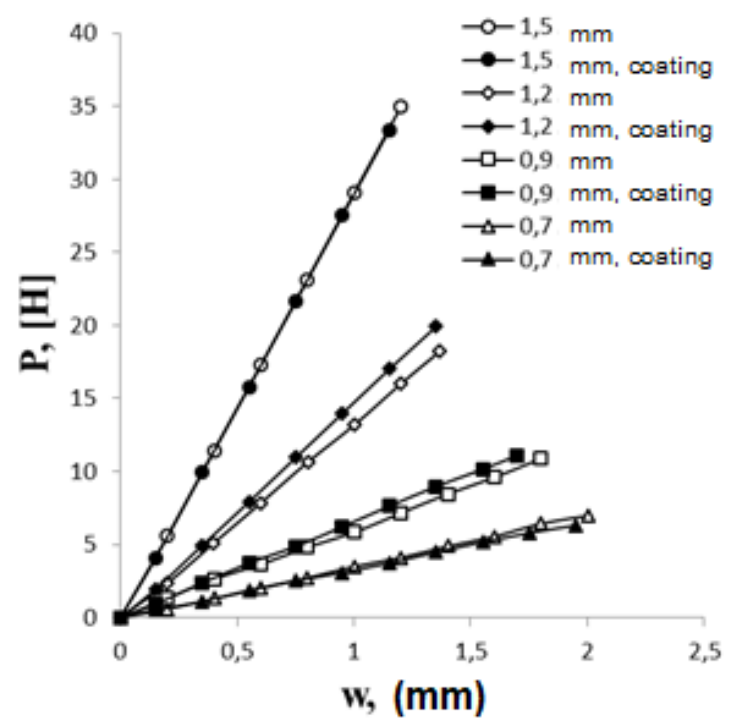

Fig. 2. Diagrams of the dependence of the deflections on the applied load obtained during the three-point bending test of plates with different thicknesses of the steel substrate with and without coatings.

Table 1. Results of bending, tensile and buckling tests of plates.

\begin{tabular}{|c|c|c|c|c|c|}
\hline Samples & & $\mathrm{E}_{\text {esg, }}, \mathrm{GPa}$ & $\sigma_{\mathrm{w}}, \operatorname{MPa}\left(20^{\circ} \mathrm{C}\right)$ & $\sigma_{\mathrm{w}}, \operatorname{MPa}\left(70^{\circ} \mathrm{C}\right)$ & $\mathrm{P}_{\mathrm{cr}}, \mathrm{N}$ \\
\hline \multirow{2}{*}{$0,7 \mathrm{~mm}$} & coated & 91 & 254 & 261 & 294 \\
\hline & withoutcover & 190 & 301 & 289 & 670 \\
\hline \multirow{2}{*}{$0,9 \mathrm{~mm}$} & coated & 105 & 255 & 272 & 423 \\
\hline & withoutcover & 180 & 307 & 307 & 977 \\
\hline
\end{tabular}




\begin{tabular}{llllll}
\hline \multirow{2}{*}{$1,2 \mathrm{~mm}$} & coated & 123 & 330 & 340 & 1032 \\
& withoutcover & 185 & 357 & 357 & 1726 \\
\cline { 2 - 5 } \multirow{2}{*}{$1,5 \mathrm{~mm}$} & coated & 159 & 331 & 368 & 2147 \\
& withoutcover & 184 & 396 & 400 & 2672 \\
\hline
\end{tabular}

The tensile test results are shown in the Fig. 3. Each diagram presented here was obtained by averaging experimental data for five samples of the same type. Note that the standard values of the tensile strength of sheets of steel can be in the range of 275-390 MPa. The values of the ultimate strength of samples without coatings obtained in the experiments lie within these limits (see Table 1), and the greater the thickness of the sample, the higher its ultimate strength. The effect of heating up to $70^{\circ} \mathrm{C}$ turns out to be insignificant (see Table 1), however, in the results obtained for plates with coatings, it can be seen that heating leads to an increase in their ultimate strength by $10-40 \mathrm{MPa}$, which may indirectly indicate the presence of a corresponding level of residual stresses in steel substrates at room temperature, which relax upon heating.
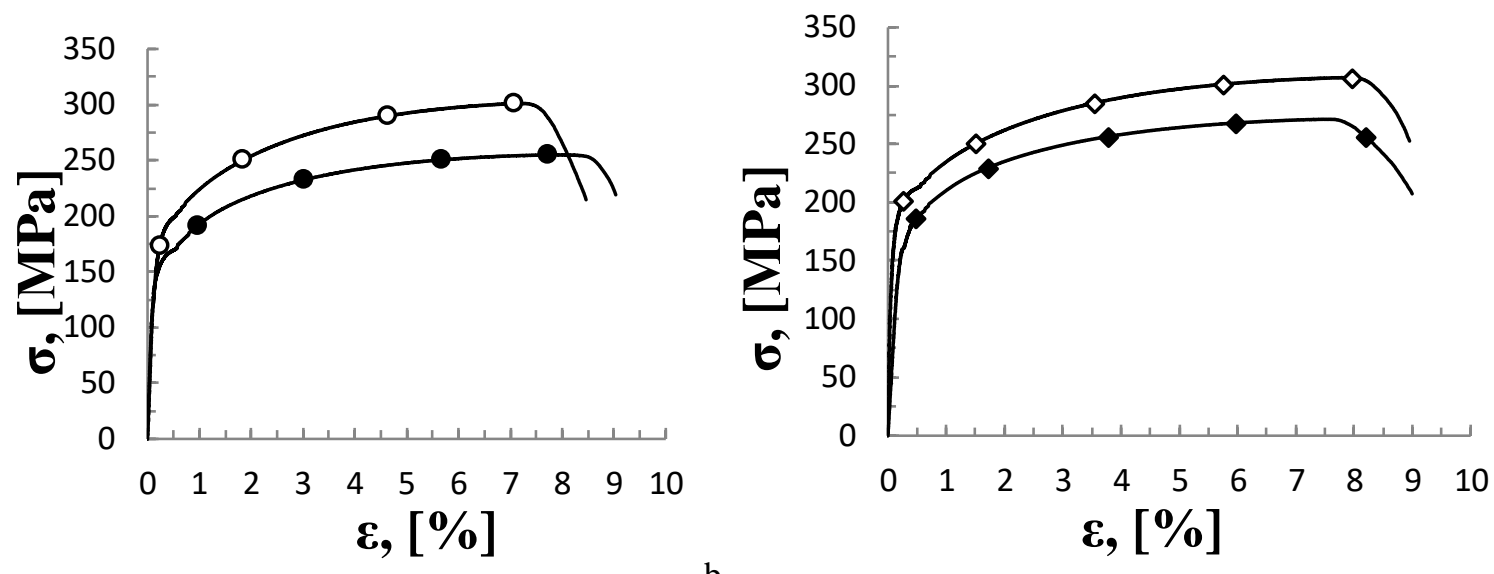

a

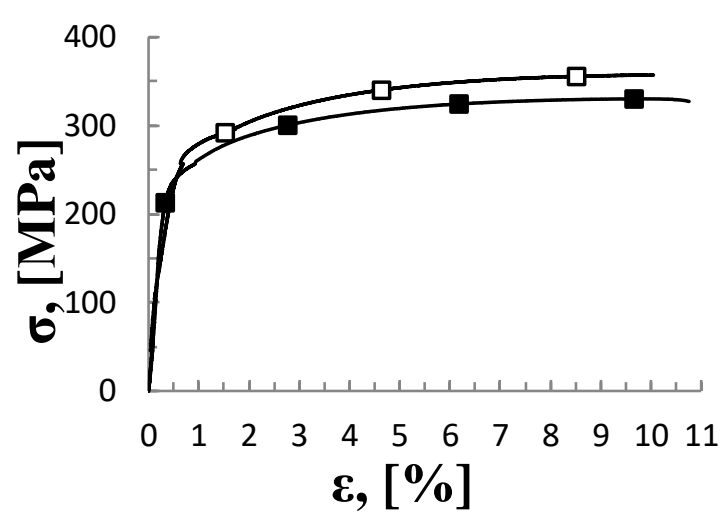

b

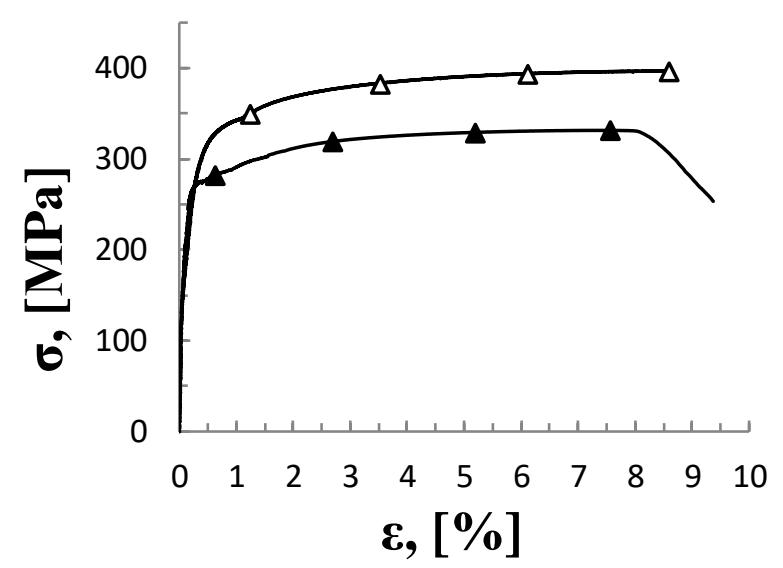

Fig. 3. Stress-strain diagrams obtained during tensile testing of samples with substrates $0.7 \mathrm{~mm}$ (a), $0.9 \mathrm{~mm}$ (b), $1.2 \mathrm{~mm}(\mathrm{c})$, and $1.5 \mathrm{~mm}(\mathrm{~d})$ with and without coatings. The designations are similar to those shown in Fig. 1.

\section{Conclusions}

In this work, it is shown that the critical buckling load for coated plates, the modulus of elasticity of which is two orders of magnitude lower than the elastic modulus of the substrate, can decrease by more than two times. This phenomenon can be explained by the influence of residual temperature stresses acting in the coating and in the substrate. Heating, polymerization and cooling of coatings when applied to steel plates leads to the occurrence of sufficiently significant residual stresses. Determination of the level of these stresses and modeling the effects of their influence on the supercritical behavior of the plates are planned to be carried out in subsequent works of the authors.

\section{References}

1. Rabinskiy, L.N. Non-stationary problem of the plane oblique pressure wave diffraction on thin shell in the shape of parabolic cylinder// PeriodicoTcheQuimica, 2019, 16(32), p. 328-337. 
2. Dobryanskiy, V.N., Rabinskiy, L.N., Tushavina, O.V. Experimental finding of fracture toughness characteristics and theoretical modeling of crack propagation processes in carbon fiber samples under conditions of additive production// PeriodicoTcheQuimica, 2019, 16(33), p. 325-336.

3. Kuznetsova, E.L., Rabinskiy, L.N. Heat transfer in nonlinear anisotropic growing bodies based on analytical solution // Asia Life Sciences, 2019, (2), p. 837-846.

4. Kuznetsova, E.L., Rabinskiy, L.N. Numerical modeling and software for determining the static and linkage parameters of growing bodies in the process of non-stationary additive heat and mass transfer//PeriodicoTcheQuimica, 2019, 16(33), p. 472-479.

5. Kuznetsova, E.L., Rabinskiy, L.N. Linearization of radiant heat fluxes in the mathematical modeling of growing bodies by the action of high temperatures in additive manufacturing //Asia Life Sciences, 2019, (2), p. 943-954.

6. Babaytsev, A.V., Kuznetsova, E.L., Rabinskiy, L.N., Tushavina, O.V. Investigation of permanent strains in nanomodified composites after molding at elevated temperatures// PeriodicoTcheQuimica, 2020, 17(34), p. 1055-1067.

7. Rabinsky, L.N., Kuznetsova, E.L. Simulation of residual thermal stresses in high-porous fibrous silicon nitride ceramics // Powder Metallurgy and Metal Ceramics, 2019, 57(11-12), p. 663-669.

8. Formalev, V.F., Kolesnik, S.A., Selin, I.A. Local non-equilibrium heat transfer in an anisotropic halfspace affected by a non-steady state point heat source // Herald of the Bauman Moscow State Technical University, Series Natural Sciences. 2018. 80(5), p. 99-111.

9. Kolesnik, S.A., Bulychev, N.A., Rabinskiy, L.N., Kazaryan, M.A. Mathematical modeling and experimental studies of thermal protection of composite materials under high-intensity effects of laser radiation// Proceedings of SPIE - The International Society for Optical Engineering. 2019. 11322, article number 113221R.

10. Anikin V.A., Vyshinsky V.V., Pashkov O.A., et al. Using the maximum pressure principle for verification of calculation of stationary subsonic flow. Herald of the Bauman Moscow State Technical University, Series Mechanical Engineering, 2019, no. 6, pp. 4-16.

11. Bulychev, N.A., Rabinskiy, L.N. Ceramic nanostructures obtained by acoustoplasma technique//Nanoscience and Technology: An International Journal, 2019, 10(3), p. 279-286.

12. O.A. Butusova. Surface Modification of Titanium Dioxide Microparticles Under Ultrasonic Treatment, International Journal of Pharmaceutical Research, 2020, Vol. 12, I. 4, pp. 2292-2296.

13. B.A. Garibyan. Mechanical Properties of Electroconductive Ceramics, International Journal of Pharmaceutical Research, 2020, Vol. 12, Supplementary Issue 2, pp. 1825-1828.

14. B.A. Garibyan. Enhancement of Mechanical Properties of Inorganic Glass under Ultrasonic Treatment, International Journal of Pharmaceutical Research, 2020, Vol. 12, Supplementary Issue 2, pp. 1829-1832.

15. O.A. Butusova. Stabilization of Carbon Microparticles by High-Molecular Surfactants, International Journal of Pharmaceutical Research, 2020, Vol. 12, Supplementary Issue 2, pp. 1147-1151.

16. A.N. Tarasova. Effect of Reagent Concentrations on Equilibria in Water-Soluble Complexes, International Journal of Pharmaceutical Research, 2020, Vol. 12, Supplementary Issue 2, pp. 1169-1172.

17. O.A. Butusova. Adsorption Behaviour of Ethylhydroxyethyl Cellulose on the Surface of Microparticles of Titanium and Ferrous Oxides, International Journal of Pharmaceutical Research, 2020, Vol. 12, Supplementary Issue 2, pp. 1156-1159.

18. A.N. Tarasova. Vibration-based Method for Mechanochemical Coating Metallic Surfaces, International Journal of Pharmaceutical Research, 2020, Vol. 12, Supplementary Issue 2, pp. 1160-1168.

19. B.A. Garibyan. Modelling of Technical Parameters of Discharge Reactor for Polymer Treatment, International Journal of Pharmaceutical Research, 2020, Vol. 12, Supplementary Issue 2, pp. 1833-1837.

20. Yu.V. Ioni. Synthesis of Metal Oxide Nanoparticles and Formation of Nanostructured Layers on Surfaces under Ultrasonic Vibrations, International Journal of Pharmaceutical Research, 2020, Vol. 12, Issue 4, pp. 3432-3435.

21. Yu.V. Ioni, A. Ethiraj. Study of Microparticles Surface Modification by Electrokinetic Potential Measuring, International Journal of Pharmaceutical Research, 2020, Vol. 12, Issue 4, pp. 3436-3439.

22. N.A. Bulychev, A.V. Ivanov. Effect of vibration on structure and properties of polymeric membranes, International Journal of Nanotechnology, 2019, Vol. 16, Nos. 6/7/8/9/10, pp. $334-343$.

23. A.N. Tarasova. Effect of Vibration on Physical Properties of Polymeric Latexes, International Journal of Pharmaceutical Research, 2020, Vol. 12, Supplementary Issue 2, pp. 1173-1180.

24. O.A. Butusova. Vinyl Ether Copolymers as Stabilizers of Carbon Black Suspensions, International Journal of Pharmaceutical Research, 2020, Vol. 12, Supplementary Issue 2, pp. 1152-1155.

25. Yu.V. Ioni. Nanoparticles of noble metals on the surface of graphene flakes, PeriodicoTcheQuimica, 2020, Vol. 17, No. 36, pp. 1199-1211.

26. N.A. Bulychev, A.V. Ivanov. Nanostructure of Organic-Inorganic Composite Materials Based on Polymer Hydrogels, International Journal of Nanotechnology, 2019, Vol. 16, Nos. 6/7/8/9/10, pp. 344 355. 
27. N.A. Bulychev, A.V. Ivanov. Study of Nanostructure of Polymer Adsorption Layers on the Particles Surface of Titanium Dioxide, International Journal of Nanotechnology, 2019, Vol. 16, Nos. 6/7/8/9/10, pp. $356-365$.

28. Yu.V. Ioni. Effect of Ultrasonic Treatment on Properties of Aqueous Dispersions of Inorganic and Organic Particles in Presence of Water-Soluble Polymers, International Journal of Pharmaceutical Research, 2020, Vol. 12, Issue 4, pp. 3440-3442.

29. Yu.V. Ioni, A. Ethiraj. New Tailor-Made Polymer Stabilizers for Aqueous Dispersions of Hydrophobic Carbon Nanoparticles, International Journal of Pharmaceutical Research, 2020, Vol. 12, Issue 4, pp. 3443-3446.

30. N.A. Bulychev, M.A. Kazaryan. Optical Properties of Zinc Oxide Nanoparticles Synthesized in Plasma Discharge in Liquid under Ultrasonic Cavitation, Proceedings of SPIE, 2019, Vol. 11322, article number 1132219.

31. Formalev, V.F., Kartashov, É.M., Kolesnik, S.A. On the Dynamics of Motion and Reflection of Temperature Solitons in Wave Heat Transfer in Limited Regions // Journal of Engineering Physics and Thermophysics, 2020, 93(1), p. 10-15.

32. Formalev, V.F., Bulychev, N.A., Kuznetsova, E.L., Kolesnik, S.A. The Thermal State of a Packet of Cooled Microrocket Gas-Dynamic Lasers // Technical Physics Letters, 2020, 46(3), p. 245-248.

33. Rabinskiy, L.N., Tushavina, O.V., Formalev, V.F. Mathematical modeling of heat and mass transfer in shock layer on dimmed bodies at aerodynamic heating of aircraft// Asia Life Sciences, 2019, (2), p. 897911.

34. Antufev, B.A., Egorova, O.V., Rabinskiy, L.N. Quasi-static stability of a ribbed shell interacting with moving load// INCAS Bulletin, 2019, 11, p. 33-39.

35. Bodryshev, V.V., Babaytsev, A.V., Rabinskiy, L.N. Investigation of processes of deformation of plastic materials with the help of digital image processing// PeriodicoTcheQuimica, 2019, 16(33), p. 865-876.

36. Astapov, A.N., Kuznetsova, E.L., Rabinskiy, L.N. Operating capacity of anti-oxidizing coating in hypersonic flows of air plasma//Surface Review and Letters, 2019, 26(2), 1850145 p.

37. Rabinskiy, L.N., Tushavina, O.V., Starovoitov, E.I. Study of thermal effects of electromagnetic radiation on the environment from space rocket activity // INCAS Bulletin, 2020, 12(Special Issue), p. 141-148.

38. Babaytsev, A.V., Orekhov, A.A., Rabinskiy, L.N. Properties and microstructure of AlSi10Mg samples obtained by selective laser melting// Nanoscience and Technology: An International Journal, 2020, 11(3), p. 213-222.

39. Egorova, O.V., Kyaw, Y.K. Solution of inverse non-stationary boundary value problems of diffraction of plane pressure wave on convex surfaces based on analytical solution//Journal of Applied Engineering Science, 2020, 18(4), p. 676-680. 